\title{
Polymer-Derived Si-Based Ceramics: Recent Developments and Perspectives
}

\author{
Aidong Xia ${ }^{1,2} \mathbb{D}$, Jie Yin ${ }^{1, *}$, Xiao Chen ${ }^{1,2}$, Xuejian Liu ${ }^{1}$ and Zhengren Huang ${ }^{1,3, *}$ \\ 1 State Key Laboratory of High Performance Ceramics and Superfine Microstructures, \\ Shanghai Institute of Ceramics, Chinese Academy of Sciences, Shanghai 200050, China; \\ xiaaidong@student.sic.ac.cn (A.X.); chenxiao@student.sic.ac.cn (X.C.); xjliu@mail.sic.ac.cn (X.L.) \\ 2 College of Materials Science and Opto-Electronic Technology, University of Chinese Academy of Sciences, \\ Beijing 100049, China \\ 3 Ningbo Institute of Materials Technology and Engineering, Chinese Academy of Sciences, \\ Ningbo 315201, China \\ * Correspondence: jieyin@mail.sic.ac.cn (J.Y.); zhrhuang@mail.sic.ac.cn (Z.H.); \\ Tel.: +86-21-6990-6070 (J.Y.); +86-21-6990-6061 (Z.H.); Fax: +86-21-6990-6023 (J.Y. \& Z.H.)
}

Received: 19 August 2020; Accepted: 15 September 2020; Published: 16 September 2020

check for updates

\begin{abstract}
Polymer derived ceramics (PDCs) are promising candidates for usages as the functionalization of inorganic Si-based materials. Compared with traditional ceramics preparation methods, it is easier to prepare and functionalize ceramics with complex shapes by using the PDCs technique, thereby broadening the application fields of inorganic Si-based ceramics. In this article, we summarized the research progress and the trends of PDCs in recent years, especially most recent three years. Fabrication techniques (traditional preparation, 3D printing, template method, freezing casting techniques, etc.), microstructural tailoring mainly via additive doping, and properties (mechanical, thermal, electrical, as well as dielectric and electromagnetic wave absorption properties) of Si-based PDCs were explicated. Meanwhile, challenges and perspectives for PDCs techniques were proposed as well, with the purpose to enlighten multiple functionalized applications of polymer-derived Si-based ceramics.
\end{abstract}

Keywords: polymer-derived ceramics; fabrication and functional techniques; properties

\section{Introduction}

As one of the oldest materials, silicon-based ceramic materials have received extensive attention due to their high hardness, high strength, wear resistance, excellent thermal stability, and chemical stability. However, they are brittle and difficult to process, which severely limits the application range of Si-based ceramics. To solve this problem, the polymer derived ceramics (PDCs) technique has been developed [1]. Compared with traditional ceramic manufacturing techniques (e.g., press molding), organic polymers were used in PDCs processing, namely "ceramic precursors" [2,3] (e.g., polysiloxane, polycarbosilane, polysilazane) instead of ceramics powders during fabrication. The preceramic polymers are formed by crosslinking and pyrolyzed under high temperature and inert atmosphere, releasing various types of low-molecular-mass gases (e.g., $\mathrm{CH}_{4}, \mathrm{H}_{2}, \mathrm{CO}, \mathrm{CO}_{2}$ ) [4] before fully converting into ceramics. Organic polymers are relatively easy to process into various shapes. Therefore, the shapes of polymers could be tailored according to specific requirements after pyrolysis. At present, the most widely studied PDCs systems are mainly PDCs-SiC [5-12], PDCs-SiOC [13-22], and PDCs-SiCN [23-32] systems.

In the past few decades, efforts had been devoted to PDCs-related materials. It was found that PDCs usually consist of a network of free carbon and rich-Si nanodomain. As Figure 1a shows, the length of rich-Si nanodomain was $1-5 \mathrm{~nm}$, while the width of nanodomain interface was $0.8-1.5 \mathrm{~nm}$ [33]. 
The microstructure of PDCs was greatly influenced by pyrolysis temperature $[6,19,22,27]$. Taking the polysilazane-derived $\mathrm{SiCN}$ as an example, Yu et al. [34] systematically summarized the microstructural evolution of PDCs under different pyrolysis temperatures. With the increase of pyrolysis temperature, the microstructural evolution can be divided into four steps: (1) at lower temperatures $\left(<800{ }^{\circ} \mathrm{C}\right)$, there occurs the formation of amorphous excess carbon (mainly $\mathrm{sp}^{3}$-hybridization) through the decomposition of aromatic hydrocarbons, evenly dispersed in the amorphous ceramic matrix (Figure 1e); (2) when the pyrolysis temperature is increased up to $800-1000^{\circ} \mathrm{C}$, the carbon layers are stacked in turbostratic order to form the basic structural unit (BSU) of free carbon, that is, nucleation. At this time, PDCs are mainly composed of turbostratic free carbon phase and amorphous rich-Si ceramic matrix (Figure 1c,d,f); (3) with the increase of pyrolysis temperature $\left(1000-1200{ }^{\circ} \mathrm{C}\right)$, the $\mathrm{C}-\mathrm{H}$ group on the outside of the BSU becomes unstable, and the residual $\mathrm{H}$ atoms are removed in the form of $\mathrm{H}_{2}$, resulting in the unsaturated carbon atoms around (Figure 1b,g); (4) after further heat treatment at high temperature $\left(>1400^{\circ} \mathrm{C}\right)$, the free carbon region continues to be rearranged and entangled with graphitic carbon nanocrystals to form a free carbon network or nanodomain (Figure 1h). Wang's group [22] found the high pyrolysis temperature is beneficial to decrease the porosity of SiOC ceramics, promoting the nucleation of $\beta-\mathrm{SiC}$ nanodomains and the graphitization of free carbon. In addition to pyrolysis temperatures, pressure $[24,35]$ and solvent [21] also affect the microstructure of PDCs. The carbothermal reduction reaction [36,37] usually occurs above $1500^{\circ} \mathrm{C}$ between free carbon and oxygen- as well as nitrogen-containing phases, leading to a reduction in the contents of carbon, oxygen, and nitrogen accompanied by the release of gaseous products (e.g., $\mathrm{CO}, \mathrm{N}_{2}$, $\mathrm{SiO}$ ) [38-40], obtaining new phases and causing the loss of mass of ceramic materials. Meng's [24] group found low pressure decreased the onset temperature of carbothermal reduction reaction, thus reducing the thermal stability of $\mathrm{SiCN}$ ceramics. Lu's group [21] found that solvents affected the carbon content and SiC crystallization during the pyrolysis of SiOC ceramic systems. Under low pyrolysis temperatures, solvents accelerated the formation of $\mathrm{SiC}$, and under high pyrolysis temperatures, the formation of $\mathrm{SiC}$ decreased with the increase of solvent content.

The recent research progress and trends of PDCs are to functionalize them through various methods (such as additive doping [30,31,41-45]) and to combine PDCs with 3D printing [4,10,13-15,29,46] to explore new techniques to fabricate PDCs. By functionalizing PDCs, they have excellent mechanical, thermal, electrical, and dielectric properties. The 3D printing technique enables PDCs to be easier to design and prepare components with required shapes and geometries. These two aspects above greatly improve the performance and broaden the potential applications of PDCs.

Polymer-derived Si-based ceramics release small molecular gases during pyrolysis and generate free paths inside the ceramics [47]. It is detrimental to the mechanical properties of ceramics, but this feature can be used to prepare ceramics with hierarchical porous structure and high specific surface area $[7,8,12,30,48]$. Meanwhile, introducing suitable additives to the preceramic polymers in the form of particles or the chemical precursors can enable PDCs with additional functions, such as catalysis $[7,18,49,50]$, electromagnetic wave absorption $[19,27,28,30,32,45,51-55]$, filtration $[8,9,11,56,57]$, and electrochemical energy storage [48,58-60]. Su's group [48] used graphene-modified PDCs-SiOC fibers to fabricate flexible ceramic cloths with hierarchical porous structure and rough surface by spinning, which can be used for high performance lithium storage application. Yin's group [30] used carbon nanowires (CNWs)-modified PDCs-SiCN to prepare materials with highly efficient electromagnetic wave absorption properties. Its minimum reflection coefficient $\left(\mathrm{RC}_{\mathrm{min}}\right)$ can reach $-51 \mathrm{~dB}$ with effective absorption bandwidth (EAB) of $3.0 \mathrm{GHz}$ at $2.7 \mathrm{~mm}$ thickness. Xu's group [56] prepared a porous PDCs-SiOC ceramic membrane with a narrow pore size distribution (the average pore diameter is $0.59 \mu \mathrm{m}$ ) by tape casting, which can be effectively used for oil-water separation of oil-in-water emulsions. Wilhelm's group [18] fabricated PDCs-SiOC with high specific surface area $\left(\sim 400 \mathrm{~m}^{2} \cdot \mathrm{g}^{-1}\right)$ by freeze casting and loading with Ni nanoparticles, and it displayed good catalytic activity; in the $\mathrm{CO}_{2}$ methanation reaction, the maximum conversion rate was 0.49 , and the maximum methane selectivity was 0.74 . In addition, by functionalizing polymer-derived Si-based ceramics, 
it can also significantly improve its mechanical [5,15,43,47,61], thermal [41,43,62-64], and electrical properties $[6,14,26,40,43]$, which could be widely used in the preparation of conductive ceramics, sensors, membranes, coatings, and components for usage under harsh environments.
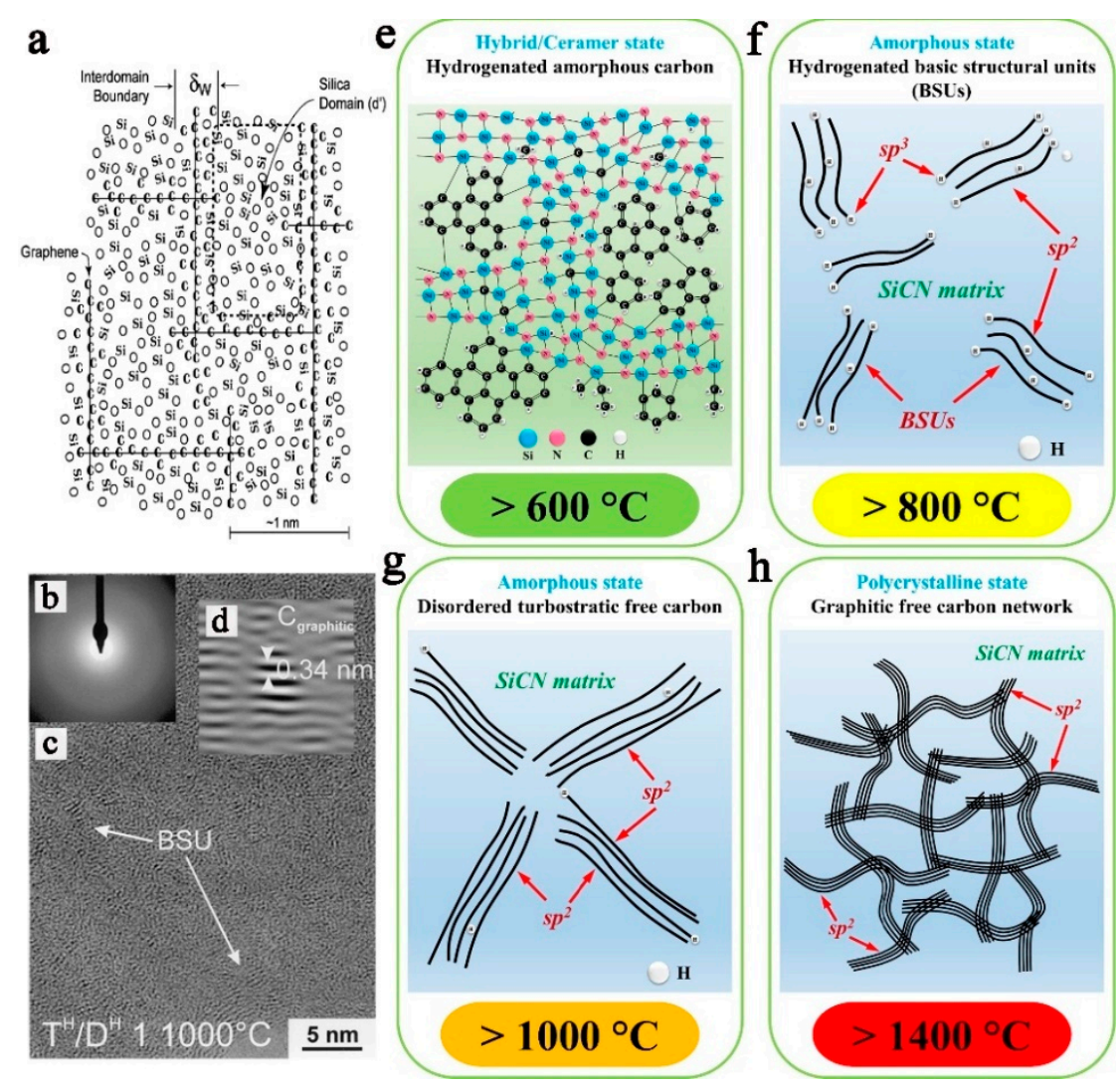

Figure 1. A model of polymer derived ceramics (PDCs) nanodomain (a); high-resolution TEM micrographs of the typical amorphous structure of PDCs (c) pyrolyzed at $1000{ }^{\circ} \mathrm{C}$. The inset (b) displays the selected area electron diffraction (SAED) patterns, indicating the amorphous feature. The inset (d) shows a basic structural unit (BSU) of free carbon with an interplanar distance of around $0.34 \mathrm{~nm}$ between the graphene layers; the structural evolution of PDCs at different pyrolysis temperatures: $>600{ }^{\circ} \mathrm{C}(\mathbf{e}),>800{ }^{\circ} \mathrm{C}(\mathbf{f}),>1000{ }^{\circ} \mathrm{C}(\mathrm{g})$ and $>1400{ }^{\circ} \mathrm{C}(\mathbf{h})$ [34]. Reproduced with permission from Yu Z., Prog. Mater. Sci.; published by Elsevier, 2020.

In this article, we summarized the recent research progress and trends of PDCs, particularly those in the last three years, and elaborated upon the forming techniques of PDCs and the functionalization and the performance of polymer-derived Si-based ceramics, etc. At the same time, the challenges faced by PDCs techniques were summarized, and prospects were proposed, with the purpose to enlighten functionalization of polymer-derived Si-based ceramics.

\section{Forming and Functionalization Techniques of PDCs}

\subsection{Forming Techniques}

With rapid development of PDCs, researchers have developed a variety of forming techniques, each technique with its own advantages, as is discussed in the following paragraphs.

\subsubsection{Traditional Forming Techniques}

Traditional forming techniques are the earliest and the most conventional techniques, and dry pressing [41,45], isostatic pressing [25,47], and tape casting [65] are more commonly used. The general route for the synthesis of PDCs using traditional forming techniques was to crosslink and solidify the 
precursor polymers and grind and sieve to obtain crosslinked polymer powders, which were then made into a green body by traditional forming techniques, and finally the green body was pyrolyzed. The traditional forming techniques are simple, low-cost, and it is easy to mix with the second phase to form functional PDCs. Most of the PDCs prepared by the traditional techniques underwent the powder densification process, and their mechanical strengths were usually higher than those of the emerging forming techniques. Zhang's group [47] used liquid polyvinylsilazane (PVSZ) with different viscosities as precursors, then crosslinked, milled, and isostatic pressing molded them. To reduce the cracks and the porosity in ceramics, PDCs thin-films with high fracture strength and high gas tightness were prepared by polymer infiltration pyrolysis (PIP) process. The PDCs thin-films were successfully used in pressure sensors and could maintain gas-tight conditions after $72 \mathrm{~h}$ without losing pressure. The fracture strength could reach $108 \mathrm{MPa}$ after only three PIP cycles. These advantages enable traditional forming techniques still favored by researchers today.

\subsubsection{D Printing Techniques}

Three-dimensional printing, also known as additive manufacturing (AM), is different from traditional cutting, grinding, and other subtractive manufacturing technologies. It is the process of manufacturing objects by sequentially depositing materials in accurate subsequent layers with the assistance of computer predesigned programs. The 3D printing techniques provide very flexible design freedom and can make parts with complex geometry without tools. With the unremitting efforts of researchers, relevant techniques of 3D printing on ceramic materials have been greatly developed. Dikshit et al. classified 3D printing techniques mainly into four categories based on different raw materials [66]: solid/impregnated feedstock, liquid (resin/ink) feedstock, powder feedstock, and hybrid feedstock. Solid/impregnated feedstock 3D printing includes techniques such as fused deposition manufacturing (FDM). Liquid (resin/ink) feedstock 3D printing includes techniques such as digital light processing (DLP). Powder feedstock 3D printing includes techniques such as selective laser sintering (SLS). Hybrid feedstock 3D printing includes techniques such as direct ink writing (DIW) [67].

DLP is a commonly used 3D printing technique for PDCs. Mixing the preceramic precursor polymer with the photosensitive resin or modifying the ceramic precursor polymer with a polymer containing photosensitive groups $[14,15,29]$ can render the preceramic precursor polymer photocuring properties, thus it can be easily printed out into various forms by DLP. He's group [29] prepared polymer-derived $\mathrm{Si}_{3} \mathrm{~N}_{4}$ honeycomb ceramics using DLP, with compressive strength and elastic modulus of $65.5 \mathrm{MPa}$ and $768.5 \mathrm{MPa}$, respectively. Lao's group [15] developed a series of SiOC ceramic precursors for DLP and prepared high-strength and lightweight SiOC ceramics with a fully dense skeleton structure. Moreover, DIW could also be used in the forming of PDCs. Colombo's group [13] combined 3D printing (DIW) and origami (Figure 2), using high printability and flexibility of silicone elastomers to obtain SiOC ceramics with complex 3D morphologies. Fabrication of PDCs by 3D printing technology can overcome the disadvantages of preparing complex-shaped components in traditional ceramic fabrication techniques and lay the foundation for broadening the application fields of ceramics.

\subsubsection{Other Forming Techniques}

Other than the novel 3D printing techniques mentioned above, many novel PDCs forming techniques are also favored by scientists. We mainly introduced template $[8,46,56,57,64]$ and freeze casting $[12,16,18,68]$ methods; both are suitable for manufacturing porous ceramics.

The template method is often combined with traditional techniques or advanced 3D printing to form PDCs products. Generally, pore-forming agents are introduced during the template molding process (mostly thermoplastic resins that could easily decompose [46], such as polyurethane (PU), polymethyl methacrylate (PMMA), polylactic acid (PA), polycarbonate (PC), polypropylene (PP), and nylon) into crosslinked and cured precursor polymers or are impregnated as a layer of precursor polymer onto the thermoplastic resin template. During high temperature pyrolysis, the thermoplastic resin is decomposed directly, and crosslinked and cured precursor polymers are converted from 
polymers into ceramics, which leaves a large number of pores in the ceramics matrix, resulting in porous ceramics or hollow ceramics. Santhosh's group [64] impregnated porous PU foam with prepared precursor solution, using the $\mathrm{PU}$ foam as a template (Figure 3a); porous $\mathrm{SiCN}(\mathrm{O})$ and $\mathrm{SiOC}$ mesh foams were fabricated and thermally characterized after pyrolysis. Colombo's group [8] added PMMA beams as a pore-forming agent to precursor, and a high-porosity open-cell $\mathrm{SiC}$ foam was obtained with a porosity of $73.4 \mathrm{vol} \%$ after pyrolysis (Figure 3b). Pearce's group [46] produced thermoplastic resin filaments using fused filament fabrication (FFF) 3D printing, then impregnated the polymer precursor solution on the filaments, and hollow SiOC ceramic filaments and ceramic skins were obtained after crosslinking and pyrolysis (Figure 3c), with thickness of less than $100 \mu \mathrm{m}$. The template method has broad application prospects in manufacturing porous and hollow ceramics.

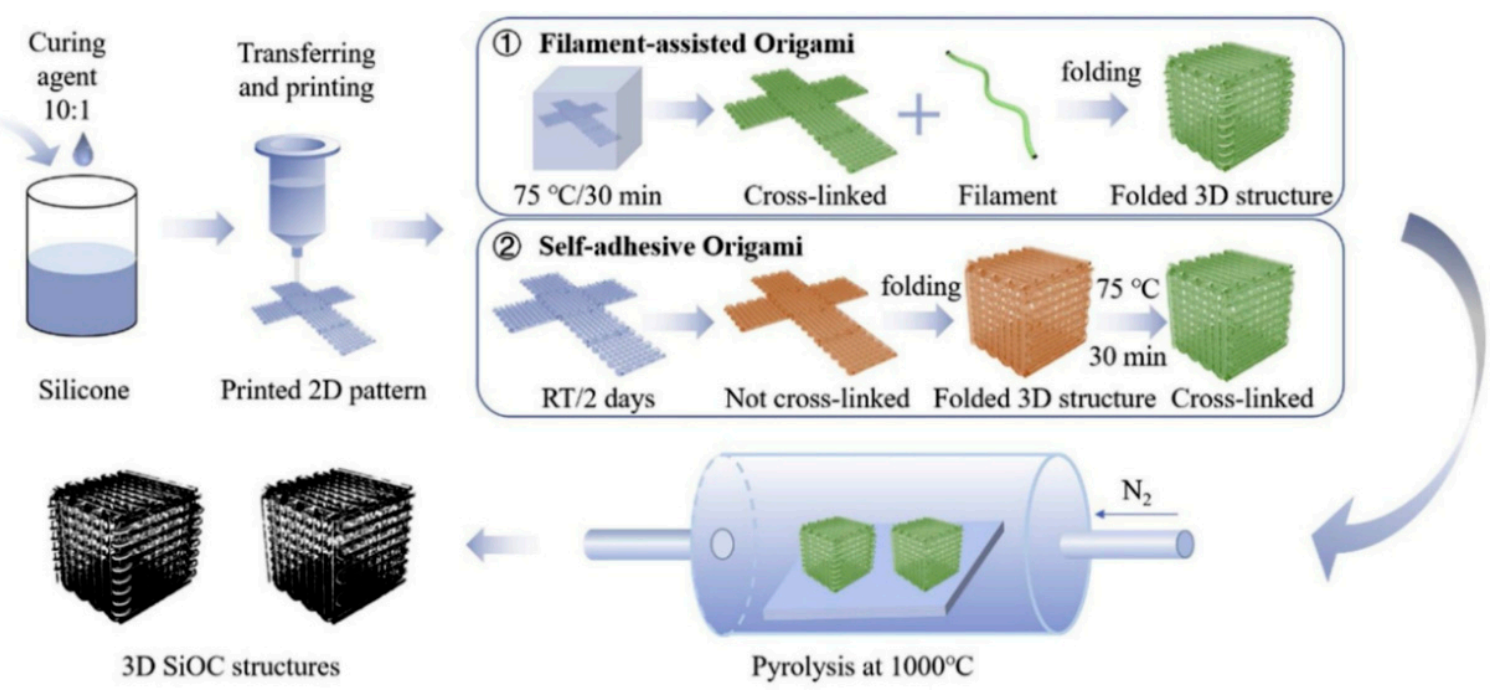

Figure 2. Schematic of the fabrication of SiOC samples with complex architecture from 3D printing and origami technique [13]. Reproduced with permission from Huang K., Addit. Manuf.; published by Elsevier, 2020.

Freeze casting is also a common method for preparing porous ceramics. As Figure $3 \mathrm{~d}$ shows, freezing casting generally consists of three steps [68]: freezing the liquid suspension; reducing the pressure to sublimate the solid solvent into gas to obtain a precursor polymer skeleton; and finally pyrolyzing the ceramic precursor skeleton to make the transition from polymer to ceramic. Different from the template method explained above, the pore-forming agent for the preparation of porous ceramics by freeze casting is solvent crystals. Therefore, compared with the template method in the narrow sense, it is easier to remove the pore-forming agent by freeze casting, and the pore morphology can be tailored by adjusting the freezing parameters [68] (solvent, suspension formulation, curing conditions, etc.). For example, Jackson [69] found that tert-butanol could easily generate prismatic pores, and cyclohexane and camphene could easily produce dendritic pore channels. This was because the Jackson $\alpha$-factors of the solvents were different. Meanwhile, in order to prepare ceramics with higher porosity, other methods can also be used in combination with freeze casting technology. Wang's group [16] used ultraviolet light-induced thiol-ene click chemistry and hydrofluoric acid (HF) etching-assisted freeze casting technology to prepare PDCs nanocomposites with hierarchical porosities. Its specific surface area was up to $494 \mathrm{~m}^{2} \cdot \mathrm{g}^{-1}$. Therefore, freeze casting technology is also a very important method for manufacturing porous PDCs. 

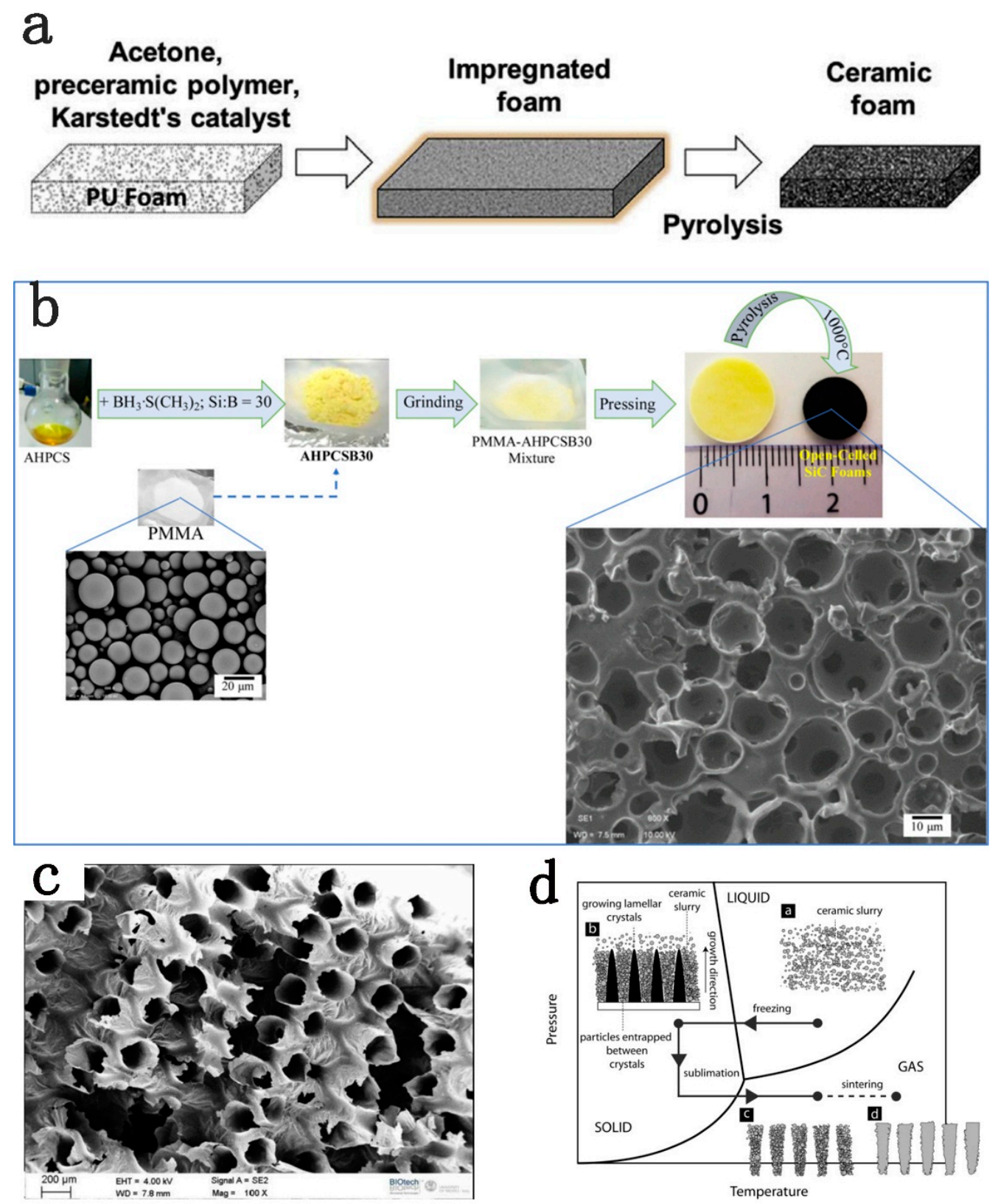

Figure 3. Schematic of impregnating polyurethane (PU) foam with precursor solution to prepare porous $\mathrm{SiCN}(\mathrm{O})$ and $\mathrm{SiOC}$ mesh foams (a); schematic of preparing high-porosity open-cell SiC foam with polymethyl methacrylate (PMMA) beams as pore-forming agent (b); hollow SiOC ceramic filaments (c); three steps of freeze casting (d) $[8,46,64,68]$. (a) reproduced with permission from Santhosh B., Ceram. Int.; published by Elsevier, 2020. (b) reproduced with permission from Santhosh B., J. Eur. Ceram. Soc.; published by Elsevier, 2019. (c) reproduced with permission from Kulkarni A., Addit. Manuf.; published by Elsevier, 2020. (d) reproduced with permission from Sylvain D., Adv. Eng. Mater.; published by Wiley, 2008.

\subsection{Functionalization Techniques}

With the development of PDCs, researchers have focused not only on the manufacturing of PDCs but also on the functionalization of PDCs. Tactics to enhance the multi-functional performance of PDCs have drawn increasing attention. At present, the functional techniques of PDCs mainly include two aspects, adding dopants and tailoring the morphology of PDCs. However, doping itself can control 
the microscopic morphology. Therefore, this section mainly introduces the impact of doping on the functionalization of PDCs.

Doping is the most common way to functionalize PDCs. By uniformly dispersing dopants with the precursor polymer, PDCs can have excellent mechanical, thermal, and electrical properties as well as dielectric and electromagnetic wave absorption properties (Figure 4). There are normally various ways of doping. The most commonly used route is to uniformly mix the uncrosslinked or the crosslinked precursor polymer with the dopants directly by magnetic stirring, ultrasonic dispersion, or ball milling $[8,14,27,28,41,44,45]$. For example, Guo's group [14] used an inorganic metal salt as a metal source and directly mixed it with a precursor polymer to prepare a metal-doped polymer-derived SiOC composite material, in which the electrical conductivity of Cu-doped SiOC ceramic was $9.32 \times 10^{-2} \mathrm{~S} \cdot \mathrm{cm}^{-1}$. In order to meet the needs of different fields, the introduction of various metal elements in PDCs is commonly used. There are generally two methods for introducing metal elements. The first is to directly mix the metal (oxide) powders in the ceramic precursors, yet it is difficult to form monodispersed solution; another one is to directly use the metal element-containing polymers, however, the process of constructing polymers containing metal elements is complicated with high cost.
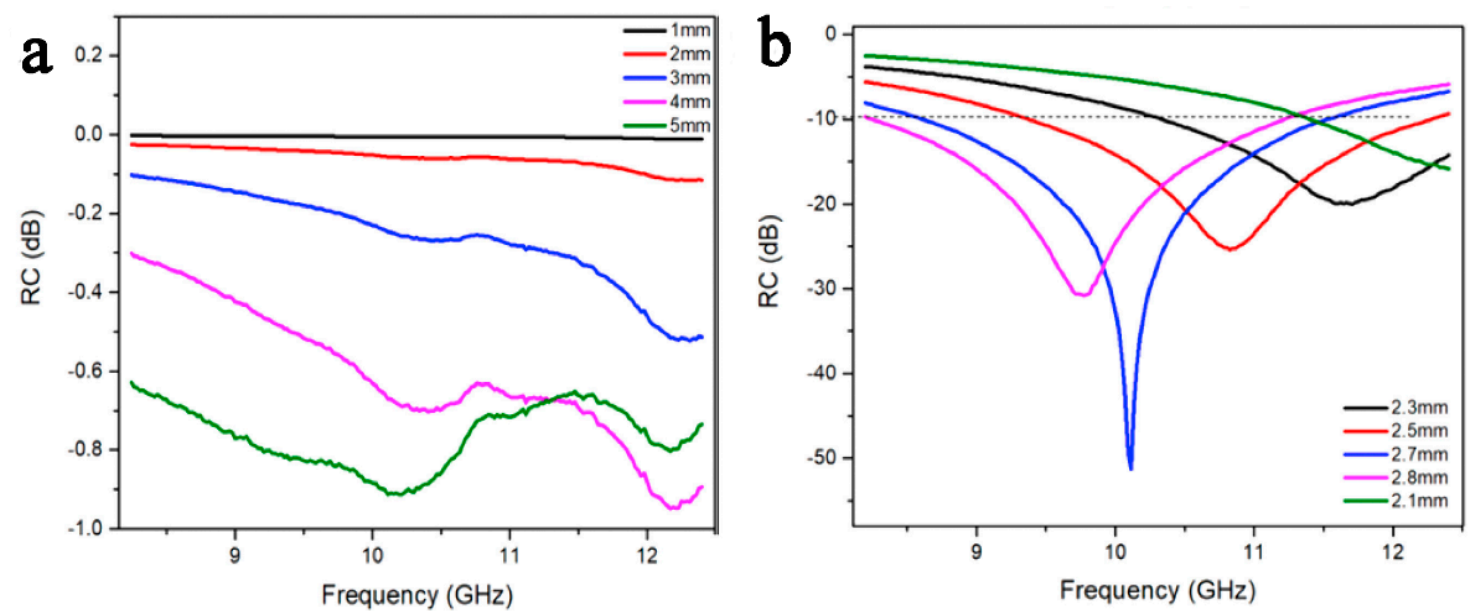

Figure 4. The influence of hierarchical carbon nanowire network on electromagnetic wave absorption properties of PDCs-SiCN. Without hierarchical carbon nanowire network (a); with $5.61 \mathrm{wt} \%$ hierarchical carbon nanowire network in PDCs-SiCN (b). The smaller the minimum reflection coefficient, the better the electromagnetic wave absorption properties of the PDCs-SiCN [30]. Reproduced with permission from Ren F., Ceram. Int.; published by Elsevier, 2019.

In addition to mixing the dopants with the precursor polymers directly, modification of the precursor polymers $[7,8,14,42,56]$ is also an effective way. Xu et al. [56] used polyhydromethylsiloxane (PHMS) and tetramethyl-tetravinyl-cyclete-trasiloxane (D4Vi) as precursors, and polydimethylsiloxane (PDMS) was added to the precursors, then the three were mixed and crosslinked. PDMS is a pore-forming agent that is quite miscible with ceramic precursors. Using PDMS to modify the ceramic precursor polymers, a porous SiOC ceramic membrane could be prepared after pyrolysis, and pore size and porosity of the ceramic membrane could be adjusted with the content of PDMS modifier. Guo's group [14] used polyhydroxymethylsiloxane (HPMS) as a precursor to prepare PDCs-SiOC by DLP, however, HPMS did not have photosensitive groups and could not perform DLP. Therefore, $\gamma$-methacryloxypropyl trimethoxy (KH570) containing photosensitive groups was used to modify HPMS, making the modified HPMS successfully used in DLP 3D printing. Whether it is direct mixing or modification of the precursor, it is a doping process and has broad application prospects in the functionalization of PDCs. 


\section{Properties}

\subsection{Mechanical Properties}

As one of the most concerned properties of inorganic Si-based ceramics, mechanical properties are favored by scientists. Researchers are eager to improve the mechanical properties of inorganic Si-based ceramics so that they can be widely used in aerospace, turbine, armor, and other fields. Unfortunately, compared with traditional high-performance ceramics, PDCs release a large amount of small molecule gases $\left(\mathrm{CH}_{4}, \mathrm{H}_{2}, \mathrm{CO}, \mathrm{CO}_{2}\right.$, etc. $)$ [4] during the transition from polymers to ceramics, generating paths for the release of small molecules. At the same time, emerging forming techniques such as freeze casting and 3D printing have their own disadvantages. The formed green-body is not fully dense but often a porous structure, and the green-body shrinks during pyrolysis. This leads to a large number of cracks and defects in the final ceramics products, which makes the polymer-derived Si-based ceramics have lower mechanical properties. Taking SiC ceramics as an example, the flexural strength of polymer-derived $\mathrm{SiC}$ is usually only a few to dozens of MPa. For example, the flexural strength of lightweight porous SiC prepared by Zhang et al. [12] using freeze casting was only 3.7-11.3 MPa. The compressive strength of the high-porosity open-cell SiC foam prepared by Colombo et al. [8] using boron-modified polycarbosilane was only 3.49 $\pm 0.59 \mathrm{MPa}$. The flexural strength of $\mathrm{SiC}$ prepared by traditional forming methods was often as high as several hundred MPa or even higher. This shortcoming severely limits the application fields of PDCs, and it is urgent to improve the mechanical properties of PDCs.

At present, there are two main methods to improve the mechanical properties of PDCs: doping $[5,8,17,70,71]$ and densification $[10,47,72]$. As mentioned above, doping is a very important method to functionalize PDCs, and the improvement of mechanical properties is also inseparable from doping. By introducing second phase particles into PDCs, the mechanical properties of PDCs can be greatly improved. The second phase particles can strengthen and toughen PDCs through crack deflection, detour, branching, pinning, and other effects. At present, the commonly used reinforcing phases are Al-salt, Zr-salt, Ti-salt, and so on. Ma's group [71] used Al-doped polysiloxane as a raw material to prepare a three-dimensional woven carbon fiber reinforced SiAlOC composites. The flexural strength of the composites was $213 \pm 13 \mathrm{MPa}$ when pyrolyzed at $1400{ }^{\circ} \mathrm{C}$. The flexural strength of $\mathrm{C} / \mathrm{ZrC} / \mathrm{SiC}$ composites prepared by Hu et al. [73] through PDCs routes could reach $319 \mathrm{MPa}$. Blugan's group [70] used titanium ethoxide (TiOET) to modify SiOC ceramics and prepared SiTiOC ceramics with Ti filler up to $30 \mathrm{wt} \%$, with a flexural strength of about $600 \mathrm{MPa}$. It can be seen that the introduction of doped phases into PDCs can greatly improve the mechanical properties of PDCs. Densification is also a way to improve the mechanical properties of PDCs. There are three commonly used densification processes: polymer impregnation pyrolysis (PIP), chemical vapor infiltration (CVI), and liquid silicon infiltration (LSI). Although these processes have different mechanisms and different densification levels, their purpose is to fill the defects such as pores and cracks of PDCs to achieve densification and improve the mechanical properties of PDCs. This article mainly discusses the functionalization of inorganic Si-based materials, thus these processes are not elaborated upon.

In addition to doping and densification, the oxygen content has a great influence on the mechanical properties of PDCs, especially the high temperature mechanical properties. As Figure 5 shows, Ru et al. [74] analyzed in detail the adverse effects of oxygen impurities on the densification process of $\mathrm{SiC}$ ceramics. Experimental analysis shows that oxygen impurities covered the surface of $\mathrm{SiC}$ particles in the form of amorphous $\mathrm{SiO}_{2}$. When the oxygen content increased from $0.55 \mathrm{wt} \%$ to $2.10 \mathrm{wt} \%$, the relative density dropped from $98.53 \%$ to $70.55 \%$ ( $28 \%$ decrease), and the hardness dropped from $27.1 \pm 0.7 \mathrm{GPa}$ to $6.7 \pm 1.1 \mathrm{GPa}(75 \%$ decrease). If the oxygen content in the sample was too high, it accelerated the carbothermal reduction reaction and released a large amount of small molecular gases, making it difficult to densify the ceramic matrix. At the same time, excessive oxygen content accelerated the abnormal growth and the coarsening of $\mathrm{SiC}$ grains during the sintering process and formed a SiOC phase, which decomposed above $1200{ }^{\circ} \mathrm{C}$, resulting in weight loss and strength reduction. In order to 
prevent abnormal grain growth and achieve high density of SiC ceramics, Ru's group proposed that the oxygen content of the powders should be limited to less than $1.30 \mathrm{wt} \%$.
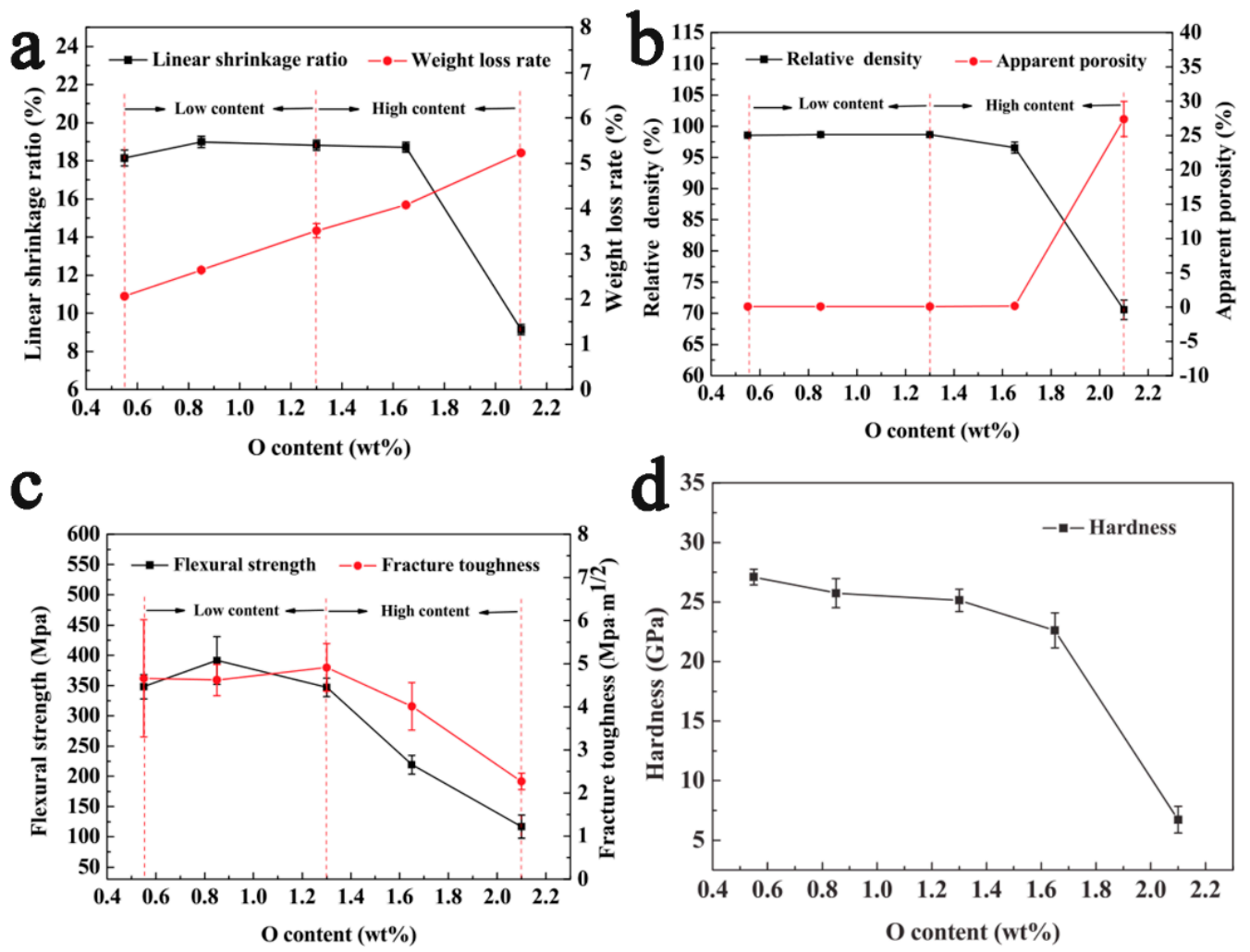

Figure 5. Effect of oxygen content on the mechanical properties of $\mathrm{SiC}$ : linear shrinking ratio and weight loss rate (a); relative density and apparent porosity (b); flexural strength and fracture toughness (c); hardness (d) [74]. Reproduced with permission from Feng D., Ceram. Int.; published by Elsevier, 2019.

\subsection{Thermal Properties}

The thermal properties of PDCs are very important for their application in high temperature fields, such as high temperature resistant coatings, insulation tiles, etc. The thermal parameters of PDCs mainly include thermal conductivity (K), coefficient of thermal expansion (CTE), specific heat capacity $(\mathrm{Cp})$, thermal diffusion rate $(\alpha)$, thermal shock resistance (TSR), etc. Among them, thermal conductivity is the most concerned thermal parameter, and we mainly focus on thermal conductivity herein. The thermal conductivity of ceramic materials with strong covalent bonds is controlled by phonon transmission [43], and the materials' microstructure (impurities, crystallinity, grain boundaries, microcracks, micropores, etc.) has a great influence on phonon scattering [41], which in turn affects the thermal properties of materials. Next, we elaborate on the influence of the microstructure of PDCs on thermal performance.

Impurities and crystallinity have a great influence on thermal properties of PDCs. The impurities include two parts-one is the phase generated by PDCs during the heat treatment (here mainly referring to free carbon), and the other is the dopants specially introduced to tailor thermal properties. The precipitation of free carbon has different effects on PDCs in different systems. For the PDCs-SiOC system [75], the precipitation of free carbon significantly increases the thermal conductivity of SiOC. It is because amorphous $\mathrm{SiOC}$ has a very low intrinsic thermal conductivity, which is approximately $1.2 \mathrm{~W} \cdot(\mathrm{m} \cdot \mathrm{K})^{-1}$ at room temperature. The thermal conductivity of the precipitated free carbon ranges from $2.2 \mathrm{~W} \cdot(\mathrm{m} \cdot \mathrm{K})^{-1}$ (amorphous carbon) to $600 \mathrm{~W} \cdot(\mathrm{m} \cdot \mathrm{K})^{-1}$ (graphite along the crystallographic direction), thus the precipitation of free carbon significantly increases the thermal conductivity of the PDCs-SiOC system. For the PDCs-SiC system [76], the precipitation of free carbon reduces the thermal 
conductivity of $\mathrm{SiC}$. This is because the intrinsic thermal conductivity of $\mathrm{SiC}$ is higher than that of SiOC. The thermal conductivity [34] of dense crystalline $\mathrm{SiC}$ is $200 \mathrm{~W} \cdot(\mathrm{m} \cdot \mathrm{K})^{-1}$, and the lowest thermal conductivity of amorphous $\mathrm{SiC}$ is $4 \mathrm{~W} \cdot(\mathrm{m} \cdot \mathrm{K})^{-1}$. Therefore, the precipitation of free carbon usually reduces the thermal conductivity of the PDCs-SiC system. The thermal conductivity of the PDCs-SiCN system is rarely mentioned in the literature. On the other hand, in order to change the thermal conductivity of PDCs, researchers usually introduce doped phases, in which B-containing compounds are very important. As Figure 6 shows, $\mathrm{Xu}$ et al. [41] added boron nitride nanotubes (BNNTs) to PDCs and found that, when the content of BNNTs was $35.4 \mathrm{vol} \%$, the thermal conductivity of PDCs was $4.123 \mathrm{~W} \cdot(\mathrm{m} \cdot \mathrm{K})^{-1}$, which was $2100 \%$ higher than that of original PDCs. Additionally, the thermal conductivity of PDCs increased with the increase of BNNTs content. When the content of BNNTs increased to $36 \pm 5 \mathrm{vol} \%$, the phenomenon of heat conduction percolation occurred. The mechanism by which BNNTs enhance the thermal conductivity of PDCs is described in detail below.

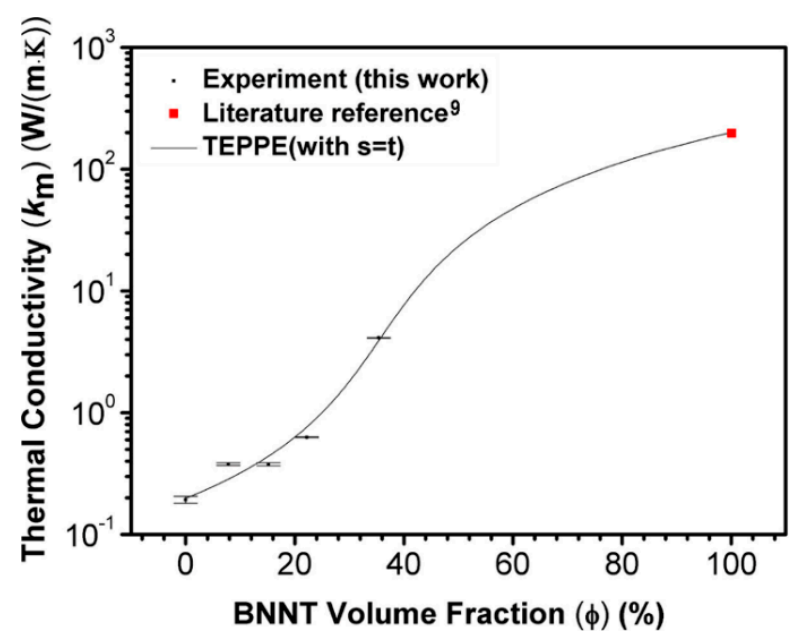

Figure 6. Influence of boron nitride nanotubes (BNNTs) content on thermal conductivity of PDCs [41].

Reproduced with permission from Xu C., J. Am. Ceram. Soc.; published by Wiley, 2019.

In addition to impurities and crystallinity, defects such as micropores, microcracks, and grain boundaries also have a great impact on the thermal properties of PDCs. The influence of these defects on thermal properties is usually carried out by affecting phonon scattering. Defects such as micropores, microcracks, and grain boundaries tend to aggravate phonon scattering during the phonon transmission process, thus reducing the thermal conductivity. In the above mentioned experiment in which BNNTs enhanced the thermal conductivity of PDCs, Xu et al. [41] believed that PDCs are porous structures, that the thermal conductivity of pores is zero, and that they can scatter phonons. After adding BNNTs, an interface is formed between PDCs and BNNTs, and the interface still scatters phonons. These two effects have a negative impact on the thermal conductivity of PDCs. However, BNNTs have a high thermal conductivity of $200 \mathrm{~W} \cdot(\mathrm{m} \cdot \mathrm{K})^{-1}$ [77], and the positive impact on the thermal conductivity of PDCs far exceeds the negative impact caused by micropores and interfaces. Therefore, the thermal conductivity of PDCs increases with the increase of BNNTs content. When the BNNTs content exceeds the percolation threshold (36 vol\%) [41], a percolation network is formed, leading to a jump in thermal conductivity. Bernard et al. [43] prepared amorphous Si-B-C powder from B-modified polycarbosilane and adjusted its thermal properties. They found that the porosity of the sintered sample decreased significantly with the increase of the B content, which in turn increased the thermal conductivity of the sample. Santhosh et al. [64] prepared polymer-derived $\mathrm{SiCN}(\mathrm{O})$ and $\mathrm{SiOC}$ reticulated foams and thermally characterized them. Experimental analysis found that, in the temperature range of $30-850{ }^{\circ} \mathrm{C}$, the linear thermal expansion coefficients of porous $\mathrm{SiCN}(\mathrm{O})$ and $\mathrm{SiOC}$ foams were $1.72 \times 10^{-6} \mathrm{~K}^{-1}$ and $1.93 \times 10^{-6} \mathrm{~K}^{-1}$, respectively. Additionally, both reticulated foams had extremely low thermal 
conductivity at room temperature; $\mathrm{SiCN}(\mathrm{O})$ was $0.03-0.2 \mathrm{~W} \cdot(\mathrm{m} \cdot \mathrm{K})^{-1}$, and $\mathrm{SiOC}$ was $0.03-0.6 \mathrm{~W} \cdot(\mathrm{m} \cdot \mathrm{K})^{-1}$. It can be seen that the microstructure of PDCs has a great influence on thermal properties.

\subsection{Electrial Properties}

The electrical properties of PDCs are another important extension of the functionalization of inorganic Si-based materials. Since conductive ceramics have been used in microelectronic systems, pacemakers, lithium-ion battery electrodes, and other fields, researchers have conducted extensive research on the electrical properties of PDCs [34]. There are many electrical parameters of PDCs; here, we mainly discuss the direct current (DC) electrical conductivity of PDCs.

The intrinsic room temperature DC electrical conductivity of PDCs varies widely, usually from $10^{-10}$ to $1 \mathrm{~S} \cdot \mathrm{cm}$, which depends on phase composition, microstructure, porosity, temperature, and other influencing factors of PDCs [34]. In order to increase the electrical conductivity of PDCs, researchers usually add conductive phases to PDCs. Sorarù et al. [78] doped boron into PDCs-SiOC, which increased the electrical conductivity by two orders of magnitude (from $10^{-5}$ to $10^{-3} \mathrm{~S} \cdot \mathrm{m}$ ). Gospodinova et al. [79] used octadecylamine-modified single-wall carbon nanotubes to enhance the electrical properties of polymer-derived $\mathrm{SiCN}$ ceramics. When $0.5 \mathrm{wt} \%$ octadecylamine-modified single-wall carbon nanotubes were added, the electrical conductivity increased five orders of magnitude (from $3 \times 10^{-9}$ to $10^{-4} \mathrm{~S} \cdot \mathrm{cm}$ ). Zhai et al. [80] prepared bulk SiCN ceramics embedded with anisotropic reduced graphene oxide aerogels (rGOAs) by adding anisotropically rGOAs to $\mathrm{SiCN}$ ceramic precursors. Experimental research found that rGOAs formed a conductive network in SiCN ceramics, which effectively improved the efficiency of charge transfer. The $1 \mathrm{wt} \%$ rGOAs could increase the electrical conductivity of PDCs-SiCN by eight orders of magnitude (from $10^{-7}$ to $157 \mathrm{~S} \cdot \mathrm{m}$ ).

The influence of microstructure on the electrical conductivity of PDCs is mainly on the precipitated free carbon. Free carbon is the main conductive phase in PDCs. Generally, the electrical conductivity of PDCs increases with the increase of free carbon content, the electrical conductivity has a sudden change in the process of increasing, and the percolation threshold $\left(\Phi_{c}\right)$ appears. As Figure 7 shows, the mechanism of the influence of free carbon on the electrical conductivity of PDCs can be divided into three parts $[34,81]$. When the free carbon content is large enough to far exceed the free carbon required to form a percolation network, the conduction mechanism is the percolation regime, and the conduction of current is achieved by directly transporting charge carriers (such as free electrons). When the free carbon content is only higher than the threshold of the tunneling process between adjacent free carbon clusters without forming a percolation network, the conductive mechanism becomes a tunneling-percolation regime. If the content of free carbon is lower than the tunneling percolation threshold, the conductive mechanism becomes a semiconductor regime.
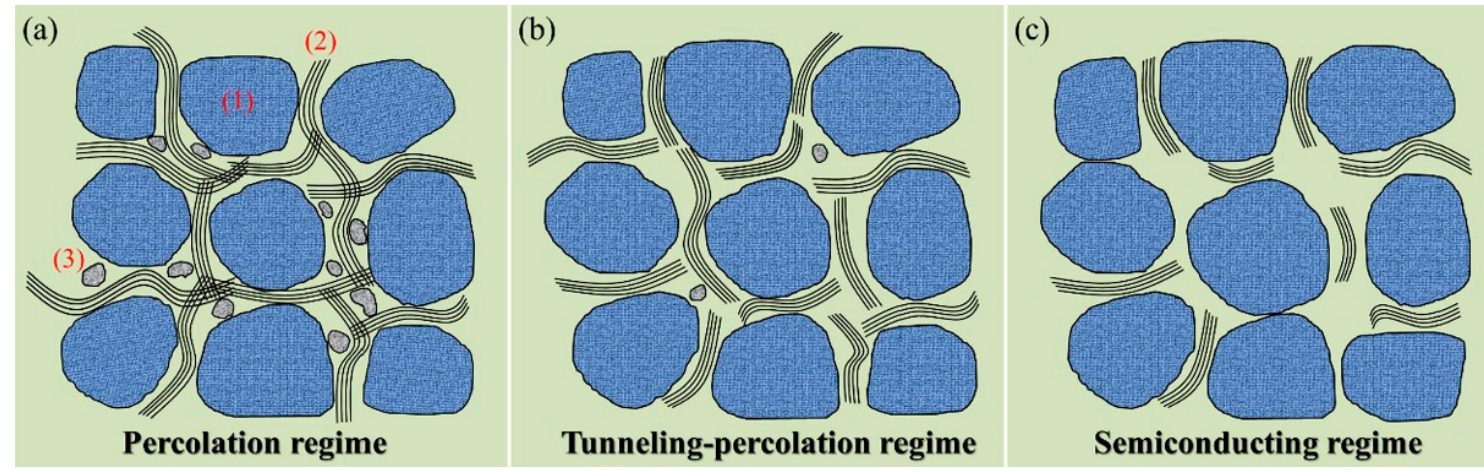

Figure 7. Models for microstructure of PDCs in different conducting regimes: (a) the free carbon content is large enough; (b) the free carbon content is only higher than the threshold of the tunneling process; (c) the free carbon content is lower than the tunneling percolation threshold. (1), (2), and (3) are SiC-based nanodomains, free carbon ribbons, and $\alpha$-SiC nanoparticles, respectively [34]. Reproduced with permission from Yu Z., Prog. Mater. Sci.; published by Elsevier, 2020. 
In addition to phase composition and microstructure, pores and temperature also have a great influence on the electrical conductivity of PDCs. Through theoretical model predictions and experimental studies, Meng et al. [26] found that porosity significantly affects the composition and the nanostructure evolution of polymer-derived $\mathrm{SiCN}$ ceramics, which in turn significantly affects electrical conductivity. As the porosity of PDCs increases from 0 to $21.32 \%$, the electrical conductivity decreases from 0.015 to $0.003 \mathrm{~S} \cdot \mathrm{cm}$. Xu et al. [6] studied the semiconductor-conductor transition of the PDCs-SiC system during the pyrolysis range of $1200-1800{ }^{\circ} \mathrm{C}$. They found that only by increasing the pyrolysis temperature could semiconductor to conductor transformation of PDCs-SiC be achieved without adding additives. This is mainly because the temperature has a great influence on the evolution of the microstructure of PDCs, which in turn has an influence on the electrical conductivity. As shown in Figure 8 , carbon clusters grow laterally by $1200-1400{ }^{\circ} \mathrm{C}$ following the $2 \mathrm{D}$ grain growth model, and the increase in electrical conductivity can be attributed to the increase in carbon order. At $1500-1600{ }^{\circ} \mathrm{C}$, $\mathrm{SiC}$ crystals begin to grow, the carbon clusters are confined to the grain boundaries, and the electric field between the closely packed nanocrystalline carbon increases, resulting in an increase in electrical conductivity. $\mathrm{SiC}$ crystals grow excessively by $1700-1800^{\circ} \mathrm{C}$, and free carbon clusters form a continuous network where electrons mainly flow through the carbon network, resulting in high conductivity of the high-temperature-pyrolyzed $\mathrm{SiC}$.

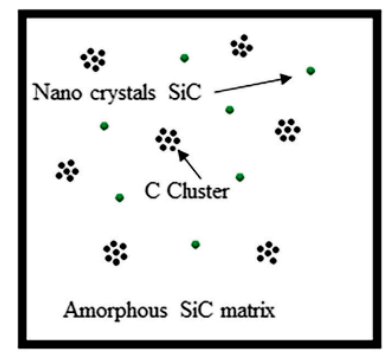

(a) $1200^{\circ} \mathrm{C}$

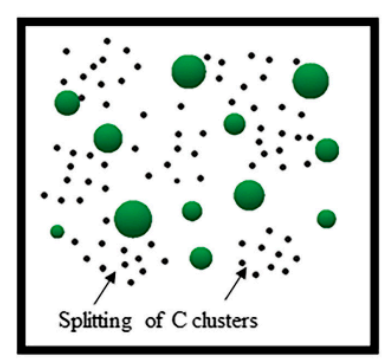

(d) $1500^{\circ} \mathrm{C}$

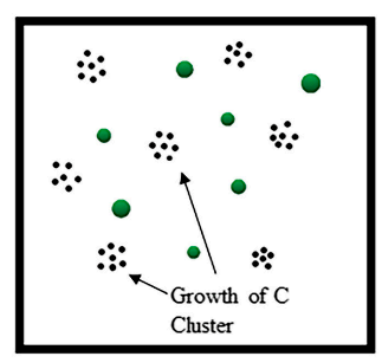

(b) $1300^{\circ} \mathrm{C}$

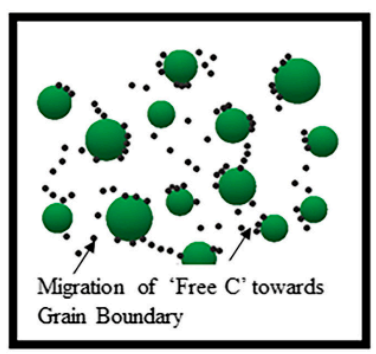

(e) $1600^{\circ} \mathrm{C}$

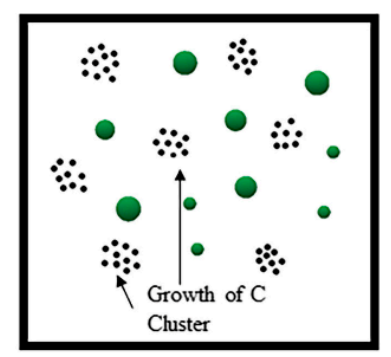

(c) $1400^{\circ} \mathrm{C}$

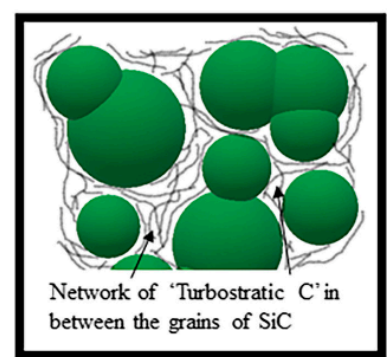

(f) $1700^{\circ} \mathrm{C}$

Figure 8. The effect of temperature on the evolution of microstructure. (a) $1200^{\circ} \mathrm{C}$ : Carbon clusters in amorphous PDCs-SiC, (b,c) $1300{ }^{\circ} \mathrm{C}-1400{ }^{\circ} \mathrm{C}$ : growth of carbon clusters and crystallization of small amount of $\mathrm{SiC}$, (d) $1500^{\circ} \mathrm{C}$ : splitting of carbon clusters into nanocrystallized carbon, (e) $1600{ }^{\circ} \mathrm{C}$ : the migration of carbon structure toward the grain boundary of silicon carbide, (f) $1700^{\circ} \mathrm{C}$ : excessive grain growth of $\mathrm{SiC}$ and formation of grain boundaries; the carbon segregated along the grain boundary forming a network of turbostratic carbon along the grain boundary of $\mathrm{SiC}$ [6]. Reproduced with permission from Xu C., J. Am. Ceram. Soc.; published by Wiley, 2019.

\subsection{Dielectric and Electromagnetic Wave Absorption Properties}

In the field of national defense, electromagnetic waves emitted by radar can accurately locate the position of the aircraft, thus electromagnetic wave absorbing materials have attracted extensive attention from researchers. An excellent electromagnetic wave absorbing material should meet the following requirements [55]: (i) strong absorption capacity and impedance matching characteristics, which means small reflection coefficient $\left(\mathrm{RC}_{\mathrm{min}}\right)$; (ii) wide effective absorption bandwidth ( $\mathrm{EAB}, \mathrm{RC}_{\min }$ is less than the corresponding frequency range of $-10 \mathrm{~dB}$ ); (iii) low density and high temperature stability; (iv) good 
mechanical properties. Among all electromagnetic wave absorbing materials, PDCs have attracted increasing attention due to their controllable microstructure, lightweight, outstanding mechanical properties, and wide absorption $[19,27,28,30,32,44,45,82]$ features.

PDCs are often not used alone for electromagnetic wave absorption materials. By introducing dopants, PDCs have stronger electromagnetic wave absorption capabilities. According to the electromagnetic wave loss mechanism, the dopant can be divided into magnetic loss materials and dielectric loss materials [28]. Magnetic materials [27,28,52] (such as Fe, Co, Ni) mainly dissipate electromagnetic waves through natural resonance or eddy current loss, while dielectric loss materials [83,84] (such as carbon and graphene) mainly dissipate electromagnetic waves through conduction loss and polarization loss. Therefore, the electromagnetic wave loss mechanism of PDCs is often a combination of magnetic loss and dielectric loss. Gong et al. [28] incorporated Co nanoparticles into $\mathrm{SiCN}$ ceramics derived from polysilazane and found that some Co nanoparticles could react with carbon to form magnetic $\mathrm{Co}_{3} \mathrm{C}$ particles, which made $\mathrm{SiCN}$ ceramics magnetic and greatly increased the magnetic loss of $\mathrm{SiCN}$. When the Co content was $2 \mathrm{wt} \%$ and the thickness was $3 \mathrm{~mm}, \mathrm{RC}_{\min }$ was $-10.9 \mathrm{~dB}$ and $\mathrm{EAB}$ was $3.3 \mathrm{GHz}$. At the same time, Gong et al. [27] also found that adding $\mathrm{NiO}$ to $\mathrm{SiCN}$ ceramics could not only increase the magnetic loss of $\mathrm{SiCN}$ ceramics, but $\mathrm{Ni}$ as a catalyst could induce the generation of carbon nanotubes (CNTs), which greatly increased the dielectric loss of SiCN ceramics; $\mathrm{RC}_{\min }$ was $-48.5 \mathrm{~dB}$ and $\mathrm{EAB}$ was $0.6 \mathrm{GHz}$ at $15.1 \mathrm{GHz}$. Ding et al. [44] directly added functionalized CNTs to the SiOC precursor. The functionalization of CNTs was to introduce-COOH to better disperse CNTs. Experimental research found that, when the CNTs content was $7.5 \mathrm{wt} \%$ and the thickness was $2.5 \mathrm{~mm}$, the $\mathrm{RC}_{\min }$ of the $\mathrm{CNTs} / \mathrm{SiOC}$ nanocomposite at $10.15 \mathrm{GHz}$ was $-60.4 \mathrm{~dB}$ and the EAB was $3.11 \mathrm{GHz}$.

In the previous section, we mentioned that Yin et al. [30] used PDCs-SiCN modified with carbon nanowires (CNWs) network to prepare efficient microwave absorbing materials. $\mathrm{RC}_{\min }$ reached $-51 \mathrm{~dB}$ at a thickness of $2.7 \mathrm{~mm}$, and the $\mathrm{EAB}$ was $3.0 \mathrm{GHz}$, showing excellent microwave absorption performance. This is because CNTs and CNWs materials have a unique one-dimensional structure with a relatively low percolation threshold, which makes it easy to form an effective conductive network [85]. In the dielectric loss, in addition to increasing the conduction loss of PDCs, CNWs have large specific surface area, rough surface, and abundant pits/defects, which also increase the polarization loss of PDCs [86]. Figure 9 depicts the attenuation process when electromagnetic waves interact with PDCs-SiCN/CNWs composites [30]. When the incident electromagnetic wave and the composite material reach impedance matching, a small amount of electromagnetic wave is reflected, and the remaining electromagnetic wave penetrates into the composite material. Once the electromagnetic wave enters the composite material, the unique hierarchical porous structure of CNWs can repeatedly scatter the incoming electromagnetic wave. Therefore, it is difficult for electromagnetic wave to leave the composite material before being attenuated. At the same time, as a typical carbon material, CNWs have excellent electrical conductivity. When CNWs form a conductive network, once an electric field is applied, the incident energy can be converted into current, resulting in strong conduction loss. Moreover, the polarization caused by the internal defects of CNWs also makes a great contribution to the stronger polarization loss. Therefore, many researchers have focused on the development of electromagnetic wave absorbing materials with special microstructures, including porous structures, core-shell structures, and heterostructures. These electromagnetic wave absorbing materials can greatly enhance the electromagnetic wave absorption performance due to interface polarization, multiple reflections, and synergistic effects [19,87-90]. 


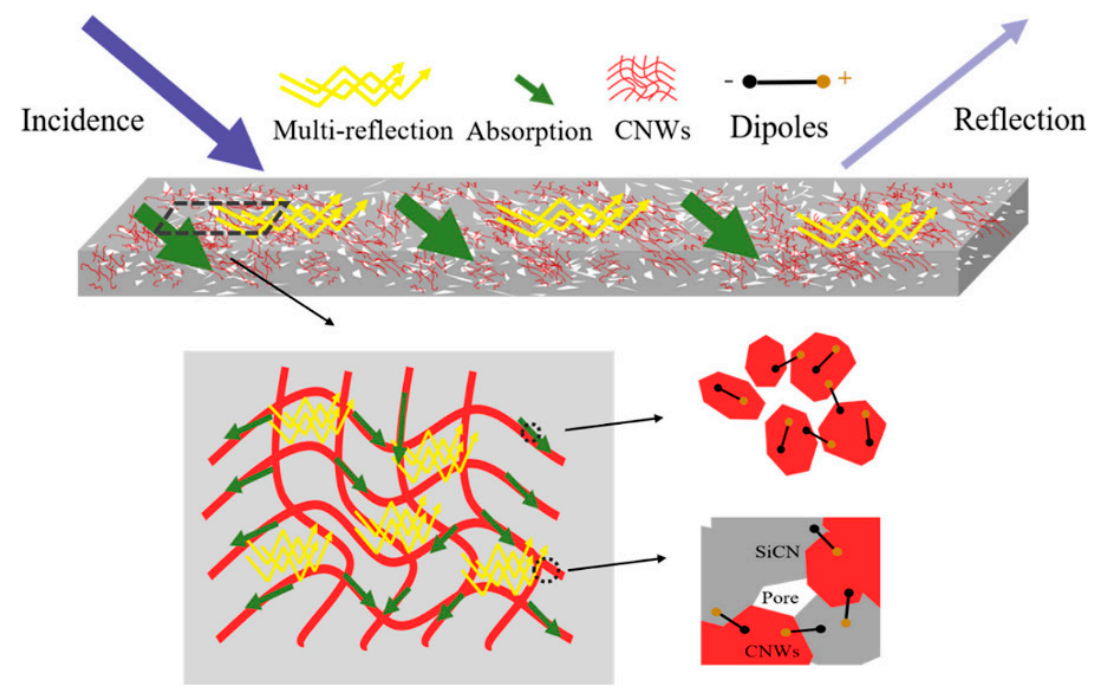

Figure 9. Schematic illustration of the interaction of electromagnetic wave with the wires and possible electromagnetic absorption mechanisms in carbon nanowires (CNWs)/SiCN composite ceramics [30]. Reproduced with permission from Ren F., Ceram. Int.; published by Elsevier, 2019.

\section{Challenges and Prospects}

The development of PDCs has a history of 50 years. In the past 50 years, researchers have conducted extensive explorations on the functionalization of polymer-derived Si-based ceramics. However, current research on optimization of microstructures and physical properties of PDCs is still limited, and many investigations on the functionalization of PDCs are still limited to the laboratory as well. These will be challenges for future research in this field. In recent years, the multi-combination of PDCs process and 3D printing techniques, biomass-derived ceramics, and biocompatibility of functionalized PDCs has attracted increasing attention. At the same time, further improving the functional characteristics of PDCs and broadening the application fields of PDCs are still hot topics in international material-related conferences. Developments of PDCs materials will have broad prospects in the near future.

\section{Conclusions}

In this review, we summarized the research progress and the trends of PDCs in recent years, especially the past three years. Fabrication techniques (traditional preparation, 3D printing, template method, freezing casting techniques, etc.), microstructural tailoring mainly via additive doping, and properties (mechanical, thermal, electrical, as well as dielectric and electromagnetic wave absorption properties) of Si-based PDCs were explicated. Meanwhile, challenges and perspectives for PDCs techniques were proposed as well, with the purpose to enlighten multiple functionalized applications of polymer-derived Si-based ceramics.

Author Contributions: Conceptualization, J.Y. and A.X.; Funding acquisition, J.Y.; Investigation, A.X.; Resources, Z.H. and X.L.; Writing-original draft, A.X.; Writing-review \& editing, J.Y. and X.C. All authors have read and agreed to the published version of the manuscript.

Funding: Financial support from: National Natural Science Foundation of China (No. 52073299, 51602325); Youth Innovation Promotion Association (CAS, No. 2018289); Shanghai Natural Science Foundation (No. 20ZR1465400); Science Foundation for Youth Scholar and Opening Project of State Key Laboratory of High-Performance Ceramics and Superfine Microstructures, Shanghai Institute of Ceramics CAS (SKL201602, SKL201902SIC), are gratefully acknowledged.

Conflicts of Interest: The authors declare no conflict of interest. 


\section{References}

1. Colombo, P.; Mera, G.; Riedel, R.; Sorarù, G.D. Polymer-Derived Ceramics: 40 Years of Research and Innovation in Advanced Ceramics. J. Am. Ceram. Soc. 2010, 93, 1805-1837. [CrossRef]

2. Fu, S.; Zhu, M.; Zhu, Y. Organosilicon Polymer-Derived Ceramics: An Overview. J. Adv. Ceram. 2019, 8, 457-478. [CrossRef]

3. Viard, A.; Fonblanc, D.; Lopez, F.D.; Schmidt, M.; Lale, A.; Durif, C.; Balestrat, M.; Rossignol, F.; Weinmann, M.; Riedel, R.; et al. Polymer Derived Si-B-C-N Ceramics: 30 Years of Research. Adv. Eng. Mater. 2018, 20, 1800360. [CrossRef]

4. Eckel, Z.C.; Zhou, C.; Martin, J.H.; Jacobsen, A.J.; Carter, W.B.; Schaedler, T.A. 3D Printing Additive Manufacturing of Polymer-Derived Ceramics. Science 2016, 351, 58-62. [CrossRef] [PubMed]

5. Laadoua, H.; Pradeilles, N.; Lucas, R.; Foucaud, S.; Clegg, W.J. Preparation of ZrC/SiC Composites by Using Polymer-Derived Ceramics and Spark Plasma Sintering. J. Eur. Ceram. Soc. 2020, 40, 1811-1819. [CrossRef]

6. Chowdhury, M.A.R.; Wang, K.; Jia, Y.; Xu, C. Semiconductor-Conductor Transition of Pristine Polymer-Derived Ceramics SiC Pyrolyzed at Temperature Range from $1200^{\circ} \mathrm{C}$ to $1800{ }^{\circ} \mathrm{C}$. J. Am. Ceram. Soc. 2019, 103, 2630-2642. [CrossRef]

7. Kaur, S.; Fischer, S.; Falta, J.; Rezwan, K.; Wilhelm, M. High Surface Area SiC(O)-Based Ceramic by Pyrolysis of Poly(ethylene glycol) Methacrylate-Modified Polycarbosilane. J. Am. Ceram. Soc. 2019, 102, 7187-7197. [CrossRef]

8. Durif, C.; Wynn, M.; Balestrat, M.; Franchin, G.; Kim, Y.W.; Leriche, A.; Miele, P.; Colombo, P.; Bernard, S. Open-Celled Silicon Carbide Foams with High Porosity from Boron-Modified Polycarbosilanes. J. Eur. Ceram. Soc. 2019, 39, 5114-5122. [CrossRef]

9. Wang, Q.; Kawano, Y.; Yu, L.; Nagasawa, H.; Kanezashi, M.; Tsuru, T. Development of High-Performance Sub-Nanoporous SiC-Based Membranes Derived from Polytitanocarbosilane. J. Membr. Sci. 2020, 598, 117688. [CrossRef]

10. Xiong, H.; Chen, H.; Chen, Z.; Xiong, X.; Zhang, D.; Zhou, K. 3D-SiC Decorated with SiC Whiskers: Chemical Vapor Infiltration on the Porous 3D-SiC Lattices Derived from Polycarbosilane-Based Suspensions. Ceram. Int. 2020, 46, 6234-6242. [CrossRef]

11. Wang, Q.; Yu, L.; Nagasawa, H.; Kanezashi, M.; Tsuru, T. High-Performance Molecular-Separation Ceramic Membranes Derived from Oxidative Cross-Linked Polytitanocarbosilane. J. Am. Ceram. Soc. 2020, 103, 4473-4488. [CrossRef]

12. Huang, Y.; Xiong, H.; Zou, J.; Zhou, K.; Zhang, D. Ultralight Porous SiC with Attracting Strength: Freeze Casting of Polycarbosilane/SiCp/Camphene-Based Suspensions. Ceram. Int. 2020, 46, 9582-9589. [CrossRef]

13. Huang, K.; Elsayed, H.; Franchin, G.; Colombo, P. Complex SiOC Ceramics from 2D Structures by 3D Printing and Origami. Addit. Manuf. 2020, 33, 101144. [CrossRef]

14. Ma, C.; He, C.; Wang, W.; Yao, X.; Yan, L.; Hou, F.; Liu, J.; Guo, A. Metal-Doped Polymer-Derived SiOC Composites with Inorganic Metal Salt as the Metal Source by Digital Light Processing 3D Printing. Virtual Phys. Prototyp. 2020, 15, 294-306. [CrossRef]

15. Li, Z.; Chen, Z.; Liu, J.; Fu, Y.; Liu, C.; Wang, P.; Jiang, M.; Lao, C. Additive Manufacturing of Lightweight and High-Strength Polymer-Derived SiOC Ceramics. Virtual Phys. Prototyp. 2020, 15, 163-177. [CrossRef]

16. Wang, X.; Schmidt, F.; Gurlo, A. Fabrication of Polymer-Derived Ceramics with Hierarchical Porosities by Freeze Casting Assisted by Thiol-Ene Click Chemistry and HF Etching. J. Eur. Ceram. Soc. 2020, 40, 315-323. [CrossRef]

17. Yu, M.; Picot, O.T.; Saunders, T.G.; Dlouhý, I.; Feng, J.; Titirici, M.M.; Mahajan, A.; Reece, M.J. Graphene-Reinforced Silicon Oxycarbide Composites Prepared by Phase Transfer. Carbon 2018, 139, 813-823. [CrossRef]

18. Schumacher, D.; Wilhelm, M.; Rezwan, K. Porous SiOC Monoliths with Catalytic Activity by in situ Formation of Ni Nanoparticles in Solution-Based Freeze Casting. J. Am. Ceram. Soc. 2020, 103, 2991-3001. [CrossRef]

19. Du, B.; He, C.; Qian, J.; Cai, M.; Wang, X.; Shui, A. Electromagnetic Wave Absorbing Properties of Glucose-Derived Carbon-Rich Ceramics Annealed at Different Temperatures. J. Am. Ceram. Soc. 2019, 102, 7015-7025. [CrossRef]

20. Ma, R.; Erb, D.; Lu, K. Flash Pyrolysis of Polymer-Derived SiOC Ceramics. J. Eur. Ceram. Soc. 2018, 38, 4906-4914. [CrossRef] 
21. Ma, R.; Lu, K.; Erb, D. Effect of Solvent in Preparation of SiOC Bulk Ceramics. Mater. Chem. Phys. 2018, 218, 140-146. [CrossRef]

22. Zhao, Z.; Niu, M.; Wang, H.; Gao, H.; Peng, K.; Zang, H.; Ma, M. Preparation and the Effects of Ion Irradiation on Bulk SiOC Ceramics. J. Eur. Ceram. Soc. 2019, 39, 832-837. [CrossRef]

23. Zhang, X.; Chen, L.; Luo, C.; Kong, J.; Bordia, R. Polymer-Derived Ceramic Microspheres with Controlled Morphology via Novel Phase Separation-Assisted Pyrolysis. J. Am. Ceram. Soc. 2016, 99, 1485-1493. [CrossRef]

24. Niu, J.; Meng, S.; Jin, H.; Li, J.; Yi, F.; Zhou, C. Thermal Stability and Nanostructure Evolution of Amorphous SiCN Ceramics during Laser Ablation in an Argon Atmosphere. J. Eur. Ceram. Soc. 2019, 39, 4535-4544. [CrossRef]

25. Ma, B.; Cao, Y.; Zhu, Y.; Li, X.; Cheng, Z. Low-Frequency Dielectric Dispersion in Polymer-Derived Amorphous Silicon Carbonitride Ceramics. J. Am. Ceram. Soc. 2019, 102, 3547-3554. [CrossRef]

26. Niu, J.; Meng, S.; Jin, H.; Yi, F.; Li, J.; Zhang, G.; Zhou, Y. Electrical Conductivity Change Induced by Porosity within Polymer-Derived SiCN Ceramics. J. Alloy. Compd. 2019, 777, 1010-1016. [CrossRef]

27. Liu, Y.; Lin, X.; Gong, H.; Zhang, Y.; Feng, Y.; Mao, J.; Xie, B. Electromagnetic Properties and Microwave Absorption Performances of Nickel-Doped SiCN Ceramics Pyrolyzed at Different Temperatures. J. Alloy. Compd. 2019, 771, 356-363. [CrossRef]

28. Wang, S.; Lin, X.; Ashfaq, M.Z.; Zhang, X.; Zhao, C.; Sheng, M.; Yang, R.; Pei, Y.; Gong, H.; Zhang, Y. Microwave Absorption Properties of SiCN Ceramics Doped with Cobalt Nanoparticles. J. Mater. Sci. Mater. Electron. 2020, 31, 3803-3816. [CrossRef]

29. Wang, M.; Xie, C.; He, R.; Ding, G.; Zhang, K.; Wang, G.; Fang, D. Polymer-Derived Silicon Nitride Ceramics by Digital Light Processing Based Additive Manufacturing. J. Am. Ceram. Soc. 2019, 102, 5117-5126. [CrossRef]

30. Ren, F.; Yin, X.; Mo, R.; Ye, F.; Zhang, L.; Cheng, L. Hierarchical Carbon Nanowires Network Modified PDCs-SiCN with Improved Microwave Absorption Performance. Ceram. Int. 2019, 45, 14238-14248. [CrossRef]

31. Li, J.; Liu, H.; Zhang, Y.; Li, Y.; Qi, D.; Chen, Z. Facile Fabrication of Fe-Doped Si-C-N Ceramic Microspheres with Flower-Like Morphology and the Infrared Extinction Property. J. Sol-Gel Sci. Technol. 2020, 94, 461-467. [CrossRef]

32. Shao, G.; Liang, J.; Zhao, W.; Zhao, B.; Liu, W.; Wang, H.; Fan, B.; Xu, H.; Lu, H.; Wang, Y.; et al. Co Decorated Polymer-Derived SiCN Ceramic Aerogel Composites with Ultrabroad Microwave Absorption Performance. J. Alloy. Compd. 2020, 813, 152007. [CrossRef]

33. Saha, A.; Raj, R.; Williamson, D.L. A Model for the Nanodomains in Polymer-Derived SiCO. J. Am. Ceram. Soc. 2006, 89, 2188-2195. [CrossRef]

34. Wen, Q.; Yu, Z.; Riedel, R. The Fate and Role of in situ Formed Carbon in Polymer-Derived Ceramics. Prog. Mater. Sci. 2020, 109, 100623. [CrossRef]

35. Li, D.; Li, Q.; Yuan, J.; Yang, Z.; Jia, D.; Cai, D.; Wang, S.; Zhou, Y.; Yu, D.; Tian, Y. Effects of High Pressure on the Low-Temperature Sintering of Dense Amorphous SiBCN Monoliths. J. Eur. Ceram. Soc. 2018, 38, 3777-3786. [CrossRef]

36. Prasad, R.M.; Mera, G.; Morita, K.; Müller, M.; Kleebe, H.J.; Gurlo, A.; Fasel, C.; Riedel, R. Thermal Decomposition of Carbon-Rich Polymer-Derived Silicon Carbonitrides Leading to Ceramics with High Specific Surface Area and Tunable Micro- and Mesoporosity. J. Eur. Ceram. Soc. 2012, 32, 477-484. [CrossRef]

37. Widgeon, S.; Mera, G.; Gao, Y.; Stoyanov, E.; Sen, S.; Navrotsky, A.; Riedel, R. Nanostructure and Energetics of Carbon-Rich SiCN Ceramics Derived from Polysilylcarbodiimides: Role of the Nanodomain Interfaces. Chem. Mater. 2012, 24, 1181-1191. [CrossRef]

38. Ionescu, E.; Papendorf, B.; Kleebe, H.J.; Riedel, R. Polymer-Derived Silicon Oxycarbide/Hafnia Ceramic Nanocomposites. Part II: Stability Toward Decomposition and Microstructure Evolution at T $\gg 1000{ }^{\circ} \mathrm{C}$. J. Am. Ceram. Soc. 2010, 93, 1783-1789. [CrossRef]

39. Burns, G.T.; Taylor, R.B.; Xu, Y.; Zangvil, A.; Zank, G.A. High-Temperature Chemistry of the Conversion of Siloxanes to Silicon Carbide. Chem. Mater. 1992, 4, 1313-1323. [CrossRef] 
40. Wen, Q.; Yu, Z.; Xu, Y.; Lu, Y.; Fasel, C.; Morita, K.; Guillon, O.; Buntkowsky, G.; Ionescu, E.; Riedel, R. $\mathrm{SiC} / \mathrm{Hf}_{\mathrm{y}} \mathrm{Ta}_{1-\mathrm{y}} \mathrm{C}_{\mathrm{x}} \mathrm{N}_{1-\mathrm{x}} / \mathrm{C}$ Ceramic Nanocomposites with $\mathrm{Hf}_{\mathrm{y}} \mathrm{Ta}_{1-\mathrm{y}} \mathrm{C}_{\mathrm{x}} \mathrm{N}_{1-\mathrm{x}}$-Carbon Core-Shell Nanostructure and the Influence of the Carbon-Shell Thickness on Electrical Properties. J. Mater. Chem. C 2018, 6, 855-864. [CrossRef]

41. Jia, Y.; Ajayi, T.D.; Morales, J.; Chowdhury, M.A.R.; Sauti, G.; Chu, S.; Park, C.; Xu, C. Thermal Properties of Polymer-Derived Ceramic Reinforced with Boron Nitride Nanotubes. J. Am. Ceram. Soc. 2019, 102, 7584-7593. [CrossRef]

42. Sun, J.; Wen, Q.; Li, T.; Wiehl, L.; Fasel, C.; Feng, Y.; Carolis, D.D.; Yu, Z.; Fu, Q.; Riedel, R. Phase Evolution of SiOC-Based Ceramic Nanocomposites Derived from a Polymethylsiloxane Modified by Hf- and Ti-alkpxides. J. Am. Ceram. Soc. 2020, 103, 1436-1445. [CrossRef]

43. Balestrat, M.; Diz, A.E.; Hanzel, O.; Tessier, D.N.; Machado, R.; Šajgalík, P.; Lenčéš, Z.; Bernard, S. Additive-Free Low Temperature Sintering of Amorphous Si-B-C Powders Derived from Boron-Modified Polycarbosilanes: Toward the Design of SiC with Tunable Mechanical, Electrical and Thermal Properties. J. Eur. Ceram. Soc. 2020, 40, 2604-2612. [CrossRef]

44. Ding, D.; Wang, J.; Yu, X.; Xiao, G.; Feng, C.; Xu, W.; Bai, B.; Yang, N.; Gao, Y.; Hou, X.; et al. Dispersing of Functionalized CNTs in Si-O-C Ceramics and Electromagnetic Wave Absorbing and Mechanical Properties of CNTs/Si-O-C Nanocomposites. Ceram. Int. 2020, 46, 5407-5419. [CrossRef]

45. Jia, Y.; Chowdhury, M.A.R.; Zhang, D.; Xu, C. Wide-Band Tunable Microwave-Absorbing Ceramic Composites Made of Polymer-Derived SiOC Ceramic and in Situ Partially Surface-Oxidized Ultra-High-Temperature Ceramics. ACS Appl. Mater. Interfaces 2019, 11, 45862-45874. [CrossRef]

46. Kulkarni, A.; Sorarù, G.D.; Pearce, J.M. Polymer-Derived SiOC Replica of Material Extrusion-Based 3-D Printed Plastics. Addit. Manuf. 2020, 32, 100988. [CrossRef]

47. Yu, Y.; Liu, Y.; Zhang, Z.; Zhang, J. Fabrication of High-Fracture-Strength and Gas-Tightness PDC Films via PIP Process for Pressure Sensor Application. J. Am. Ceram. Soc. 2020, 103, 3541-3551. [CrossRef]

48. Sang, Z.; Yan, X.; Wen, L.; Su, D.; Zhao, Z.; Liu, Y.; Ji, H.; Liang, J.; Dou, S. A Graphene-Modified Flexible SiOC Ceramic Cloth for High-Performance Lithium Storage. Energy Storage Mater. 2020, 25, 876-884. [CrossRef]

49. Canuto, A.S.T.; Mooste, M.; Kibena, P.E.; Matisen, L.; Merisalu, M.; Kook, M.; Sammelselg, V.; Tammeveski, K.; Wilhelm, M.; Rezwan, K. Polymer-Derived Co/Ni-SiOC(N) Ceramic Electrocatalysts for Oxygen Reduction Reaction in Fuel Cells. Catal. Sci. Technol. 2019, 9, 854-866. [CrossRef]

50. Lale, A.; Schmidt, M.; Mallmann, M.D.; Bezerra, A.V.A.; Acosta, E.D.; Machado, R.A.F.; Demirci, U.B.; Bernard, S. Polymer-Derived Ceramics with Engineered Mesoporosity: From Design to Application in Catalysis. Surf. Coat. Technol. 2018, 350, 569-586. [CrossRef]

51. Luo, C.; Jiao, T.; Gu, J.; Tang, Y.; Kong, J. Graphene Shield by SiBCN Ceramic: A Promising High-Temperature Electromagnetic Wave-Absorbing Material with Oxidation Resistance. ACS Appl. Mater. Interfaces 2018, 10, 39307-39318. [CrossRef]

52. Liu, Y.; Feng, Y.; Gong, H.; Guo, X.; Lin, X.; Xie, B.; Zhang, Y. Electromagnetic Wave Absorption Properties of Europium-Doped SiCN (Fe) Polymer-Derived Ceramics. J. Mater. Sci. Mater. Electron. 2018, 29, 12496-12502. [CrossRef]

53. Feng, Y.; Guo, X.; Gong, H.; Zhang, Y.; Liu, Y.; Lin, X.; Mao, J. Microwave Absorption Performance of PDCs-SiCN(Fe) Ceramics with Negative Imaginary Permeability. Ceram. Int. 2018, 44, 10420-10425. [CrossRef]

54. Song, C.; Liu, Y.; Ye, F.; Wang, J.; Cheng, L. Microstructure and Electromagnetic Wave Absorption Property of Reduced Graphene Oxide-SiCnw/SiBCN Composite Ceramics. Ceram. Int. 2020, 46, 7719-7732. [CrossRef]

55. Duan, W.; Yin, X.; Li, Q.; Schlier, L.; Greil, P.; Travitzky, N. A Review of Absorption Properties in Silicon-Based Polymer Derived Ceramics. J. Eur. Ceram. Soc. 2016, 36, 3681-3689. [CrossRef]

56. Dong, B.; Wang, F.; Yang, M.; Yu, J.; Hao, L.; Xu, X.; Wang, G.; Agathopoulos, S. Polymer-Derived Porous SiOC Ceramic Membranes for Efficient Oil-Water Separation and Membrane Distillation. J. Membr. Sci. 2019, 579, 111-119. [CrossRef]

57. Zhang, Z.; Bao, Y.; Sun, X.; Chen, K.; Zhou, M.; He, L.; Huang, Q.; Huang, Z.; Chai, Z.; Song, Y. Mesoporous Polymer-Derived Ceramic Membranes for Water Purification via a Self-Sacrificed Template. ACS Omega 2020, 5, 11100-11105. [CrossRef]

58. Mukherjee, S.; Ren, Z.; Singh, G. Molecular Polymer-Derived Ceramics for Applications in Electrochemical Energy Storage Devices. J. Phys. D Appl. Phys. 2018, 51, 463001. [CrossRef] 
59. Mujib, S.B.; Cuccato, R.; Mukherjee, S.; Franchin, G.; Colombo, P.; Singh, G. Electrospun SiOC Ceramic Fiber Mats as Freestanding Electrodes for Electrochemical Energy Storage Applications. Ceram. Int. 2020, 46, 3565-3573. [CrossRef]

60. Sujith, R.; Chauhan, P.K.; Gangadhar, J.; Maheshwari, A. Graphene Nanoplatelets as Nanofillers in Mesoporous Silicon Oxycarbide Polymer Derived Ceramics. Sci. Rep. 2018, 8, 17633. [CrossRef]

61. Schelm, K.; Abreu Morales, E.; Scheffler, M. Mechanical and Surface-Chemical Properties of Polymer Derived Ceramic Replica Foams. Materials 2019, 12, 1870. [CrossRef]

62. Ionescu, E.; Bernard, S.; Lucas, R.; Kroll, P.; Ushakov, S.; Navrotsky, A.; Riedel, R. Polymer-Derived Ultra-High Temperature Ceramics (UHTCs) and Related Materials. Adv. Eng. Mater. 2019, 21, 1900269. [CrossRef]

63. Yu, M.; Zhang, G.; Saunders, T. Wood-Derived Ultra-High Temperature Carbides and Their Composites: A Review. Ceram. Int. 2020, 46, 5536-5547. [CrossRef]

64. Santhosh, B.; Vakifahmetoglu, C.; Ionescu, E.; Reitz, A.; Albert, B.; Sorarù, G.D. Processing and Thermal Characterization of Polymer Derived $\mathrm{SiCN}(\mathrm{O})$ and SiOC Reticulated Foams. Ceram. Int. 2020, 46, 5594-5601. [CrossRef]

65. Canuto, A.S.T.; Fernandes, K.V.; Pereira, C.; Simões, M.; Wilhelm, M.; Rezwan, K. Novel Tape-Cast SiOC-Based Porous Ceramic Electrode Materials for Potential Application in Bioelectrochemical Systems. J. Mater. Sci. 2019, 54, 6471-6487. [CrossRef]

66. Dikshit, V.; Goh, G.D.; Nagalingam, A.P.; Goh, G.L.; Yeong, W.Y. Recent Progress in 3D Printing of Fiber-Reinforced Composite and Nanocomposites. In Fiber-Reinforced Nanocomposites: Fundamentals and Applications; Elsevier: Amsterdam, The Netherlands, 2020; pp. 371-394. [CrossRef]

67. Franks, G.V.; Tallon, C.; Studart, A.R.; Sesso, M.L.; Leo, S. Colloidal Processing: Enabling Complex Shaped Ceramics with Unique Multiscale Structures. J. Am. Ceram. Soc. 2017, 100, 458-490. [CrossRef]

68. Deville, S. Freeze-Casting of Porous Ceramics: A Review of Current Achievements and Issues. Adv. Eng. Mater. 2008, 10, 155-169. [CrossRef]

69. Jackson, K.A. Constitutional Supercooling Surface Roughening. J. Cryst. Growth 2004, 264, 519-529. [CrossRef]

70. Vallachira, W.S.P.; Muller, E.; Clement, P.; Jang, J.; Kakkava, E.; Panusa, G.; Psaltis, D.; Maniura, W.K.; Rottmar, M.; Brugger, J.; et al. In Vitro Cytocompatibility Assessment of Ti-Modified, Silicon-Oxycarbide-Based, Polymer-Derived, Ceramic-Implantable Electrodes under Pacing Conditions. ACS Appl. Mater. Interfaces 2020, 12, 17244-17253. [CrossRef] [PubMed]

71. Hu, Z.; Ma, Q.; Xu, T. High-Temperature Stability of Carbon Fiber Reinforced Polymer-Derived SiAlOC Composites under Different Environment. Ceram. Int. 2019, 45, 1434-1438. [CrossRef]

72. Ma, B.; Zhu, Y.; Wang, K.; Sun, Z. PIP Process Greatly Influencing the Microstructure and Electrical Conductivity of Polymer-Derived SiCN Ceramics. J. Alloy. Compd. 2019, 784, 1084-1090. [CrossRef]

73. Chen, S.; Zhang, C.; Zhang, Y.; Zhao, D.; Hu, H.; Xiong, X. Effects of Polymer Derived SiC Interphase on the Properties of C/ZrC Composites. Mater. Des. 2014, 58, 102-107. [CrossRef]

74. Feng, D.; Ren, Q.; Ru, H.; Wang, W.; Jiang, Y.; Ren, S.; Zhang, C. Effect of Oxygen Content on the Sintering Behaviour and Mechanical Properties of SiC Ceramics. Ceram. Int. 2019, 45, 23984-23992. [CrossRef]

75. Mazo, M.A.; Tamayo, A.; Caballero, A.C.; Rubio, J. Electrical and Thermal Response of Silicon Oxycarbide Materials Obtained by Spark Plasma Sintering. J. Eur. Ceram. Soc. 2017, 37, 2011-2020. [CrossRef]

76. Rahman, A.; Zunjarrao, S.C.; Singh, R.P. Effect of Degree of Crystallinity on Elastic Properties of Silicon Carbide Fabricated Using Polymer Pyrolysis. J. Eur. Ceram. Soc. 2016, 36, 3285-3292. [CrossRef]

77. Yang, J.; Downes, R.; Yu, Z.; Park, J.G.; Liang, R.; Xu, C. Strong and Ultra-Flexible Polymer-Derived Silicon Carbonitride Nanocomposites by Aligned Carbon Nanotubes. Ceram. Int. 2016, 42, 13359-13367. [CrossRef]

78. Sorarù, G.D.; Kacha, G.; Campostrini, R.; Ponzoni, A.; Donarelli, M.; Kumar, A.; Mariotto, G. The Effect of B-Doping on the Electrical Conductivity of Polymer-Derived Si(B)OC Ceramics. J. Am. Ceram. Soc. 2017, 100, 4611-4621. [CrossRef]

79. Shopova, G.D.; Burghard, Z.; Dufaux, T.; Burghard, M.; Bill, J. Mechanical and Electrical Properties of Polymer-Derived Si-C-N Ceramics Reinforced by Octadecylamine-Modified Single-Wall Carbon Nanotubes. Compos. Sci. Technol. 2011, 71, 931-937. [CrossRef]

80. Shen, C.; Calderon, J.E.; Barrios, E.; Soliman, M.; Khater, A.; Jeyaranjan, A.; Tetard, L.; Gordon, A.; Seal, S.; Zhai, L. Anisotropic Electrical Conductivity in Polymer Derived Ceramics Induced by Graphene Aerogels. J. Mater. Chem. C 2017, 5, 11708-11716. [CrossRef] 
81. Wen, Q.; Yu, Z.; Liu, X.; Bruns, S.; Yin, X.; Eriksson, M.; Shen, Z.J.; Riedel, R. Mechanical Properties and Electromagnetic Shielding Performance of Single-Source-Precursor Synthesized Dense Monolithic $\mathrm{SiC} / \mathrm{HfC}_{\mathrm{x}} \mathrm{N}_{1-\mathrm{x}} / \mathrm{C}$ Ceramic Nanocomposites. J. Mater. Chem. C 2019, 7, 10683-10693. [CrossRef]

82. Wang, Y.; Guo, X.; Feng, Y.; Lin, X.; Gong, H. Wave Absorbing Performance of Polymer-Derived SiCN(Fe) Ceramics. Ceram. Int. 2017, 43, 15551-15555. [CrossRef]

83. Cao, W.; Wang, X.; Yuan, J.; Wang, W.; Cao, M. Temperature Dependent Microwave Absorption of Ultrathin Graphene Composites. J. Mater. Chem. C 2015, 3, 10017-10022. [CrossRef]

84. Wen, B.; Cao, M.; Hou, Z.; Song, W.; Zhang, L.; Lu, M.; Jin, H.; Fang, X.; Wang, W.; Yuan, J. Temperature Dependent Microwave Attenuation Behavior for Carbon-Nanotube/Silica Composites. Carbon 2013, 65, 124-139. [CrossRef]

85. Pan, H.; Yin, X.; Xue, J.; Cheng, L.; Zhang, L. In-situ Synthesis of Hierarchically Porous and Polycrystalline Carbon Nanowires with Excellent Microwave Absorption Performance. Carbon 2016, 107, 36-45. [CrossRef]

86. Ren, F.; Yu, H.; Wang, L.; Saleem, M.; Tian, Z.; Ren, P. Current Progress on the Modification of Carbon Nanotubes and Their Application in Electromagnetic Wave Absorption. RSC Adv. 2014, 4, 14419-14431. [CrossRef]

87. Zhao, H.; Cheng, J.; Zhu, J.; Wang, Y. Ultralight CoNi/rGO Aerogels Toward Excellent Microwave Absorption at Ultrathin Thickness. J. Mater. Chem. C 2019, 7, 441-448. [CrossRef]

88. Abdalla, I.; Shen, J.; Yu, J.; Li, Z.; Ding, B. $\mathrm{Co}_{3} \mathrm{O}_{4} /$ Carbon Composite Nanofibrous Membrane Enabled High-Efficiency Electromagnetic Wave Absorption. Sci. Rep. 2018, 8, 12402. [CrossRef] [PubMed]

89. Pang, H.; Pang, W.; Zhang, B.; Ren, N. Excellent Microwave Absorption Properties of the h-BN-GO-Fe $3 \mathrm{O}_{4}$ Ternary Composite. J. Mater. Chem. C 2018, 6, 11722-11730. [CrossRef]

90. Huangfu, Y.; Liang, C.; Han, Y.; Qiu, H.; Song, P.; Wang, L.; Kong, J.; Gu, J. Fabrication and Investigation on the $\mathrm{Fe}_{3} \mathrm{O}_{4}$ /Thermally Annealed Graphene Aerogel/Epoxy Electromagnetic Interference Shielding Nanocomposites. Compos. Sci. Technol. 2019, 169, 70-75. [CrossRef]

(C) 2020 by the authors. Licensee MDPI, Basel, Switzerland. This article is an open access article distributed under the terms and conditions of the Creative Commons Attribution (CC BY) license (http://creativecommons.org/licenses/by/4.0/). 